(c) 2021 Universidad Nacional Autónoma de México, Facultad de Estudios Superiores Zaragoza.

Este es un artículo Open Access bajo la licencia CC BY-NC-ND (http://creativecommons.org/licenses/by-nc-nd/4.0/).

TIP Revista Especializada en Ciencias Químico-Biológicas, 24: 1-13, 2021.

https://doi.org/10.22201/fesz.23958723e.2021.366

\title{
Exposición al plomo: Conocimientos sobre los efectos en ovarios y el impacto a la salud reproductora femenina
}

\author{
Selene Karinna Trujillo-Vázquez ${ }^{1 \mathrm{a}}$, Edmundo Bonilla-González ${ }^{1 \mathrm{c}}$, \\ Rafael Valencia-Quintana ${ }^{2}$, Juana Sánchez-Alarcon², \\ Rosa María López-Durán ${ }^{\mathbf{1}}$ y José Luis Gómez-Olivares ${ }^{1 \mathrm{~b}}$ \\ ${ }^{1}$ Depto. de Ciencias de la Salud, Universidad Autónoma Metropolitana-Unidad Iztapalapa. \\ Avenida San Rafael Atlixco \#186, Colonia Vicentina, 09340 Alcaldía de Iztapalapa, Ciudad \\ de México, México. ${ }^{2}$ Laboratorio "Rafael Villalobos-Pietrini" de Toxicología Genómica y \\ Química Ambiental, Universidad Autónoma de Tlaxcala, Ambiente y Genética UATLX- \\ CA-223. Km 10.5 Autopista Tlaxcala-San Martín, Ixtacuixtla, 90120. Tlaxcala, México. \\ E-mails: ${ }^{a}$ nauyaca@outlook.com, ${ }^{b}$ gool@xanum.uam.mx, ${ }^{c}$ mundo@xanum.uam.mx
}

\begin{abstract}
RESUMEN
El plomo $(\mathrm{Pb})$ es un metal pesado altamente tóxico de importancia industrial cuya presencia continúa siendo un riesgo en el ambiente. Las concentraciones de este metal sobrepasan los límites establecidos por las agencias gubernamentales, amenazando la salud de la población, principalmente en los países en desarrollo. El $\mathrm{Pb}$ afecta a varios sistemas del organismo, incluyendo al reproductor. En este trabajo se revisan las investigaciones sobre sus efectos tóxicos en los ovarios, abordando estudios realizados in vivo e in vitro en mamíferos, principalmente rata, ratón y humanos, desde el año 2000 al 2020. Entre los principales hallazgos se encuentran las modificaciones del balance óxido-reducción (REDOX) celular, la separación de las células de la granulosa que conforman al folículo y el aumento de la atresia folicular, entre otros, que alteran los procesos reproductores. La realización de más estudios interdisciplinarios ayudará a mejorar la comprensión de los mecanismos de acción del $\mathrm{Pb}$ en el ovario y el riesgo a la salud reproductora femenina.
\end{abstract}

Palabras clave: $\mathrm{Pb}$, gónadas, hormonas, exposición, balance REDOX, folículos ováricos, atresia, plomo.

Lead exposure: Knowledge of the effects on the ovaries and its impact on female reproductive health

\begin{abstract}
Lead $(\mathrm{Pb})$ is a highly toxic heavy metal of industrial importance; its presence continues to be a risk in the environment. The concentrations of this metal exceed the limits established by government agencies, representing a menace to the health of the population, mainly in developing countries. $\mathrm{Pb}$ affects several systems, including the reproductive system. In this work, research on its toxic effects of $\mathrm{Pb}$ on the ovaries is reviewed, addressing studies carried out in vivo and in vitro in mammals, mainly rats, mice and humans from 2000 to 2020. Among the main findings are the modification of the cellular REDOX balance, separation of granulosa cells that conform the follicle, and increased follicular atresia, among others, which consequently alter the reproductive process. Further interdisciplinary studies will help improve the understanding of the mechanisms of action of Pb in the ovary, as well as the risk it represents for female reproductive health.
\end{abstract}

Keywords: $\mathrm{Pb}$, gonads, hormones, exposition, REDOX balance, ovarian follicles, atresia, lead. 


\section{INTRODUCCIÓN}

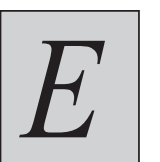

1 plomo $(\mathrm{Pb})$ es un metal pesado cuya presencia ha formado parte de la historia humana.Al identificarse procesos patológicos generados por la exposición a este metal, las agencias gubernamentales en diversos países se encargaron de normar sus niveles en el ambiente, con la finalidad de proteger la salud de la población (Wu, Cobbina, Mao, Xu, Zhang \& Yang, 2016). A pesar de esto, el Pb continúa siendo un elemento de importancia industrial en diversos países y una amenaza para los seres vivos y el ambiente (Schell, Burnitz \& Lathrop, 2010; Ospina, 2015).

La frecuencia de exposición, no ocupacional, a concentraciones ambientales por encima de los límites máximos establecidos por agencias gubernamentales es mayor en países en desarrollo (Liu et al., 2017; Pelfrene \& Douay, 2017; Nazarpour, Watts, Madhani \& Elahi, 2019). Las fallas en el tratamiento de agua potable (Maloney, Bayon, Zaqia \& Lahiri, 2018), así como el dolo en las pruebas de calidad de este líquido que enmascaran niveles peligrosos de $\mathrm{Pb}$ (Roy \& Edwards, 2019) continúan siendo un riesgo para la población. El grado de exposición al $\mathrm{Pb}$ varía en cada país (Iqbal, 2012; Caravanos et al., 2014; Hobi, 2014; Oben-Gyasi, 2019), la vía más común de ingreso al organismo es a través de la ingestión por agua o alimentos contaminados (Fitamo, Itana \& Olsson, 2007; Fuentes-Gandara, Pinedo-Hernández, Marrugo-Negrete \& Díez, 2016; Luo, Meng, Ye, Wang \& Bai, 2016; Tamayo-y-Ortiz et al., 2016; Jarvis, Quy, Macadam, Edwards \& Smith, 2018; Ngole-Jeme, Ekosse \& Songca, 2018) y, si bien puede ingresar por inhalación y absorción dérmica, estos últimos suelen ser menos frecuentes (Agency for Toxic Substances and Disease Registry, 2011; Bindler, 2011). Debido a que el $\mathrm{Pb}$ afecta la fertilidad, resulta de suma importancia ahondar en los conocimientos sobre sus mecanismos de toxicidad en el aparato reproductor femenino (Chang et al., 2006; Hsiao-Ling, Hsiao-Jui, Hsin-Yi, Kai-Wei \& Ling-Chu, 2015).

La fertilidad femenina depende del ovario, que tiene un papel central en la maduración sexual a través de la producción hormonal, así como en la generación y desarrollo de los ovocitos (Hoyer, 2014). Debido a que el $\mathrm{Pb}$ afecta al sistema endocrino y reproductor (Doumouchtsis, Doumouchtsis, Doumouchtsis \& Perrea, 2009; Sharma \& Bhattacharya, 2014), impacta negativamente a la salud reproductora femenina a corto y largo plazo (Junaid, Chowdhury, Narayan, Shanke \& Saxena, 2010). Se sabe que éste puede ejercer efectos y ser acumulado en el sistema óseo incluso a concentraciones traza (Bloom, Louis, Sundaram, Kostyniak \& Jain, 2011) al ser liberado durante la gestación, la lactancia o la osteoporosis (Gulson, Mizon, Korsch, Palmer \& Donnelly, 2003; Center for Disease Control and Prevention [CDC], 2010; Winiarska-Mieczan \& Kwiecien, 2016), se convierte en un riesgo potencial para las mujeres y su descendencia, aun si ha cesado la exposición (Nampoothiri \& Gupta, 2008; Matthews \& Phillips, 2010). Por esta razón, en el presente trabajo se llevó a cabo una revisión de los estudios realizados acerca de los efectos del $\mathrm{Pb}$ sobre los ovarios.

\section{Metodología}

Se realizó una búsqueda de los términos "ovary lead exposure", "granulose cells $\mathrm{Pb}$ ", "Pb + ovary" "lead acetate female gonads", "Lead exposure female gonads" en los buscadores PubMed, Pubchem, Elsevier, ScienceDirect, JSTOR, Mendeley, SciELO, SpringerLink y Google Scholar, para llevar a cabo una revisión bibliográfica de artículos científicos que abordan los efectos del $\mathrm{Pb}$ de manera aislada o en combinación con otros compuestos sobre el aparato reproductor femenino, principalmente en ratón, rata y humano, así como las técnicas in vitro en tejido ovárico; se consultaron sólo un par de trabajos en bovinos, ovejas, y un trabajo con gallinas (estos últimos por ser modelos experimentales más recientes).

El criterio empleado se basó en la selección de publicaciones posteriores al año 2000 enfocadas principalmente, pero no limitadas a los ovarios como órgano completo o a los componentes celulares del mismo. Sólo se mencionan trabajos previos al año 2000 fundamentales para entender la acción del $\mathrm{Pb}$ en los ovarios. El orden cronológico no demerita la naturaleza del trabajo realizado con gónadas femeninas, por esta razón se consideraron estudios de años más recientes en los que utilizan técnicas plenamente establecidas como: la histología, los marcadores moleculares y el cultivo celular. Se modificó la unidad en que se reportan los niveles de exposición de cada artículo a ppm para mantener un formato homogéneo.

\section{El ovario y las especies reactivas de oxígeno (ERO)}

El ovario es el órgano que produce los gametos y hormonas femeninos (Hoyer, 2014). Está compuesto por células germinales (ovocitos) y somáticas (células de la granulosa, de la teca y del estroma), cuyas interacciones dictan la formación y la maduración de los folículos, la ovulación, así como la formación del cuerpo lúteo (Richards \& Pangas, 2010). Los procesos relacionados a la maduración folicular y a la ovulación son controlados por las hormonas folículo estimulante $(\mathrm{FSH})$ y la luteinizante (LH), que son secretadas por la glándula pituitaria, que a su vez es regulada por la hormona liberadora de la gonadotropina (GnRH) (Richards \& Pangas, 2010). Estas hormonas funcionan como mensajeros en el ovario, interactuando con distintos componentes celulares que permitirán el desarrollo adecuado de los gametos femeninos, así como el mantenimiento de las funciones ováricas normales (Figura 1). El éxito reproductor dependerá de estas interacciones. Los gametos femeninos son producidos cuando el organismo es un feto y no son regenerados, disminuyendo en número a lo largo de la vida (Hoyer, 2014).

En el ovario, la producción de especies reactivas de oxígeno (ERO) es un fenómeno normal durante la esteroidogénesis, la maduración folicular, la reanudación de la meiosis y la ovulación (Sugino, 2005). La generación de las ERO es contrarrestada 


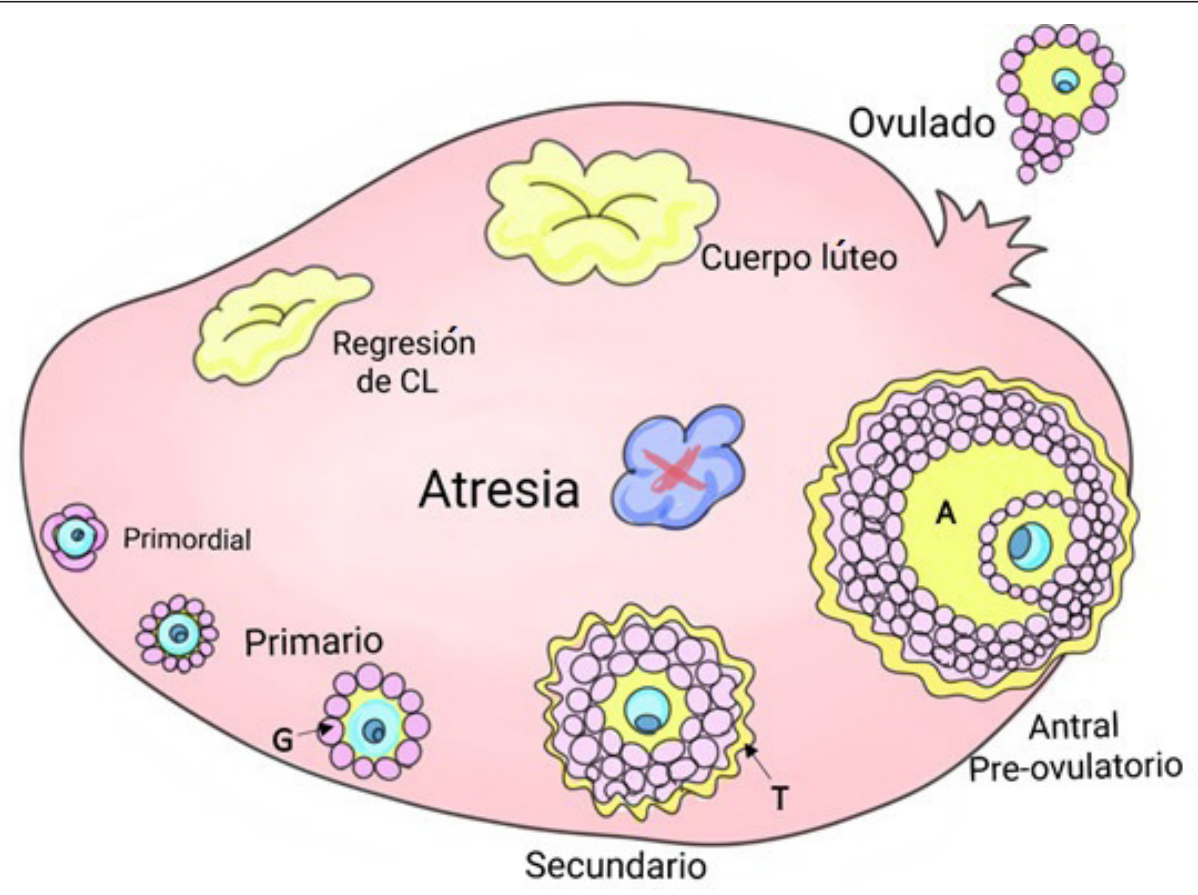

Figura 1. Representación del proceso de maduración folicular. La FSH controla el crecimiento de las células de la granulosa(G), así como la producción de estradiol, mientras que la LH regula la ovulación y la luteinización folicular (Richards \& Pangas, 2010). Hoyer (2014) describe que la forma más inmadura del folículo se denomina "primordial", donde el ovocito es rodeado por una unicapa de células de la granulosa. Una vez activado, madura para volverse un folículo primario, donde se rodeará por una unicapa de células de la granulosa cuboidales. Posteriormente se convertirá en un folículo secundario, en el cual las células de la granulosa proliferan para formar una capa multicelular, mientras se genera una capa de células de la teca interna (T). Éstas interactuarán entre sí para producir la $17 \beta$-estradiol (el principal estrógeno asociado a la función ovárica). Conforme avanza el desarrollo, comienza a formarse una cavidad llena de fluido (el antro, A). El folículo más grande es denominado "Antral" o "preovulatorio". Aquellos que no ovulan mueren en un proceso conocido como atresia. En la etapa final, el ovocito es liberado y entra al oviducto rodeado por varias capas de células de la granulosa. Las células residuales en el ovario son infiltradas y comienzan a luteinizarse, formando un cuerpo lúteo maduro, el cual producirá progesterona (importante para el proceso de implantación). Al final del ciclo ovárico, si no hay fecundación, el cuerpo lúteo sufre una regresión. Elaboración personal.

por enzimas como la superóxido-dismutasa (SOD), catalasa (CAT), glutatión-peroxidasa (GPx), glutatión reductasa (GR), y la molécula del glutatión (Glut), entre otras, cuyo equilibrio es crucial en la salud reproductora. El $\mathrm{Pb}$ tiene la capacidad de aumentar los niveles de las ERO como el peróxido de hidrógeno $\left(\mathrm{H}_{2} \mathrm{O}_{2}\right)$, anión superóxido $\left(\mathrm{O}_{2}^{-}\right)$y radical hidroxilo $\left(\mathrm{OH}^{\circ}\right)$ al inactivar estas enzimas antioxidantes (AOX) (Ahamed \& Siddiqui, 2007), alterando el balance óxido-reducción (REDOX). Las células lúteas y las de la granulosa tanto en ratas como en humanos responden al $\mathrm{H}_{2} \mathrm{O}_{2}$ y al $\mathrm{O}_{2}^{-}$con una rápida inhibición en la síntesis hormonal (Behrman, Kodaman, Preston, \& Gao, 2001 ; Hayashi, Miyamoto, Konari, Ohtani \& Fukui, 2003; Agarwal, Gupta \& Sharma, 2016; Masudul-Hoque, Umehara, Kawai \& Shimada, 2021). El radical OH` induce daño al DNA en las células lúteas e inhibe la síntesis de proteínas, interrumpiendo el desarrollo folicular y la ovulación (Agarwal et al., 2016). Esta inactivación interfiere con los procesos de reparación de daños al DNA ocasionados por las ERO, disminuyendo el número de óvulos disponibles y, a pesar de ser posible un embarazo, el daño al material genético compromete la estabilidad de los cromosomas heredados (Titus et al., 2013). Los daños inducidos han sido descritos en diversos estudios a lo largo de los años (Tabla I).

El ingreso y los efectos del $\mathrm{Pb}$ en las células.

$\mathrm{El} \mathrm{Pb}$ puede ser absorbido a través del sistema respiratorio o por el tracto gastrointestinal. En el organismo se distribuirá a órganos como el riñón, el hígado, el cerebro, las gónadas y los huesos (Valdivia-Infantas, 2005; Beyersmann \& Hartwig, 2008), siendo el último, el compartimento en el que se acumula durante las exposiciones crónicas (Patocka \& Cerny, 2003; ATSDR, 2011). Se sabe que el calcio almacenado en los huesos es transferido a través de la circulación materna para ayudar a la rápida mineralización de los huesos del feto, proceso que continúa posterior al parto a través de la leche materna (Kovacs, 2001). La movilización del calcio a partir del hueso materno que ocurre durante el embarazo y la lactancia estimula también la movilización del $\mathrm{Pb}$ almacenado en el hueso, elevando sus 
Tabla I. Estudios desde el año 2000 que demuestran los efectos del plomo sobre los ovarios a nivel celular y fisiológico.

\begin{tabular}{|c|c|c|}
\hline Referencia & Modelo empleado & Hallazgos significativos \\
\hline Aglan et al. (2020) & Cultivo celular & $\begin{array}{l}\text { Aumento de las ERO, atenuación de la expresión génica Nrf2, reducción de la } \\
\text { SOD y la CAT, el aumento de las proteínas carboniladas induce la apoptosis } \\
\text { en las células de la granulosa }\end{array}$ \\
\hline $\begin{array}{l}\text { Bruno-Nascimento et } \\
\text { al. }(2016)\end{array}$ & Rattus norvegicus & $\begin{array}{l}\text { Acumulación del Pb en la leche de las hembras gestantes y en los ovarios de la } \\
\text { descendencia }\end{array}$ \\
\hline Canaz et al. (2010) & $\begin{array}{l}\text { Tejidos tumorales de } \\
\text { pacientes }\end{array}$ & $\begin{array}{l}\text { Concentraciones de } \mathrm{Pb} \text {, mayores, en tejidos de tumores limítrofes y malignos, } \\
\text { proyecciones papilares y tejido capsular }\end{array}$ \\
\hline Dhir \& Dhand (2010) & Rattus norvegicus & $\begin{array}{l}\text { Ciclo estral irregular, disminución de un } 40 \% \text { en la fertilidad. Atresia en los } \\
\text { folículos en distintas fases del desarrollo. }\end{array}$ \\
\hline $\begin{array}{l}\text { Dumitrescu et al. } \\
\text { (2015) }\end{array}$ & Rattus norvegicus & $\begin{array}{l}\text { Acumulación del Pb directamente correlacionada con la concentración. } \\
\text { Dispersión celular en los folículos, destrucción del parénquima ovárico, } \\
\text { necrosis en las células y en las glándulas uterinas, desarrollo de quistes } \\
\text { ováricos y folículos atrésicos. }\end{array}$ \\
\hline $\begin{array}{l}\text { Dumitrescu et al. } \\
\text { (2014) }\end{array}$ & Rattus norvegicus & $\begin{array}{l}\text { Disminución significativa de la FSH, la progesterona y el estradiol, aumento } \\
\text { de la LH }\end{array}$ \\
\hline Jasim-Sodani (2017) & Mus musculus & $\begin{array}{l}\text { La mayoría de los folículos con corona radiata degenerada, ovocito degradado, } \\
\text { sin zona pelúcida visible y apoptosis masiva. Reducción en el número de } \\
\text { células de la granulosa y dispersas. Aumento en la cantidad de folículos } \\
\text { atrésicos. }\end{array}$ \\
\hline Junaid et al. (2010) & Mus musculus & $\begin{array}{l}\text { Disminución en el número de folículos primordiales a antrales, distintos } \\
\text { grados de atresia en los folículos secundarios a antrales. Degeneración de los } \\
\text { ovocitos, edema en la médula ovárica y los folículos de Graaf con desarrollo } \\
\text { incompleto. }\end{array}$ \\
\hline Lefevre (2001) & Mus musculus & $\begin{array}{l}\text { Menor cantidad de folículos primordiales, mayor cantidad de folículos } \\
\text { atrésicos. Muchos ovocitos habían reanudado la meiosis. Folículos antrales } \\
\text { atrésicos con células de la granulosa despegadas y cuyos ovocitos reiniciaron } \\
\text { la meiosis. Teca hipertrófica }\end{array}$ \\
\hline Ma et al. (2020) & Gallus domesticus & $\begin{array}{l}\text { Acumulación relacionada directamente con el nivel de exposición. } \\
\text { Disminución en la expresión de GPx y Nrf2 }\end{array}$ \\
\hline $\begin{array}{l}\text { Nampoothiri \& Gupta } \\
(2008)\end{array}$ & Rattus norvegicus & $\begin{array}{l}\text { Disminución leve del estradiol y la progesterona. Disminución de la actividad } \\
\text { esteroidogénica en las células de la granulosa. Reducción del glutatión, } \\
\text { la catalasa y la superóxido dismutasa, aumento en los marcadores de la } \\
\text { lipoperoxidación }\end{array}$ \\
\hline $\begin{array}{l}\text { Paksy, Gati, Naray \& } \\
\text { Rajczy (2001) }\end{array}$ & $\begin{array}{l}\text { Cultivo celular } \\
\text { (humano) }\end{array}$ & $\begin{array}{l}\text { Acumulación del } \mathrm{Pb} \text { en el fluido folicular, disminución en la producción de } \\
\text { progesterona, los niveles de } \mathrm{Pb} \text { en el líquido folicular fueron mayores que en } \\
\text { el suero. Despegamiento gradual de las células de la granulosa }\end{array}$ \\
\hline $\begin{array}{c}\text { Sharma \& } \\
\text { Bhattacharya (2014) }\end{array}$ & Mus musculus & $\begin{array}{l}\text { Pérdida en el peso de los ovarios dependiente de la duración del tratamiento, } \\
\text { disminución del número de ovocitos y folículos que entraron a la fase de } \\
\text { crecimiento. Células de la granulosa atrofiadas y reducción en el diámetro de } \\
\text { los folículos. }\end{array}$ \\
\hline Taupeau et al. (2003) & $\begin{array}{l}\text { Cultivo celular } \\
\text { (ratón) }\end{array}$ & $\begin{array}{l}\text { Disminución en la cantidad de folículos primordiales disponibles, aumento } \\
\text { de los folículos atrésicos, células de la teca hipertróficas. La mayoría de los } \\
\text { ovocitos en los folículos atrésicos habían reiniciado la meiosis. Disminución } \\
\text { de transcriptos de P450 aromatasa y ERB } \beta \text { en las células de la granulosa. }\end{array}$ \\
\hline
\end{tabular}


niveles en la sangre materna. El plomo movilizado se convierte entonces no sólo en una fuente endógena de exposición para la madre, sino también para el feto y el niño lactante (Gulson et al., 2003; CDC, 2010; Winiarska-Mieczan \& Kwiecien, 2016). La importancia de ésto radica en el hecho de que este metal puede afectar al organismo aún a bajas concentraciones, ya que el ion $\mathrm{Pb}^{2+}$ ha sido asociado a modificaciones en las rutas metabólicas y en las vías de señalización hormonal y molecular que afectan negativamente al organismo (Martínez-Riera, Sant-Yacumo \& Riera de Martínez-Villa, 2001; Beyersmann \& Hartwig, 2008).

El Pb ingresa a la célula por vías como el intercambio iónico, o anclado a grupos -SH (tioles o sulfhidrilo) de proteínas transmembranales (Kirberger, Wong, Jiang \& Yang, 2013), canales iónicos, o transportadores del glutatión, transportadores de iones calcio o vesículas (Chiu \& Yang, 2012; Gonick, 2011). Sus efectos patológicos son multifactoriales al interrumpir la actividad de las enzimas AOX, inhibir competitivamente la absorción de iones metálicos importantes, e interactuar con los compuestos - $\mathrm{SH}$, alterando diversos procesos celulares (Jomova \& Valko, 2011; Kirberger et al., 2013).

La enzima delta aminolevulínico deshidrogenasa (ALAD) (Godwin, 2001) y la molécula del glutatión (Mah \& Jalilehvand,2013) tienen la capacidad de formar enlaces con iones metálicos. Estos componentes del sistema REDOX se anclarán con mayor facilidad al $\mathrm{Pb}$, inactivándose $\mathrm{o}$ modificándose en el proceso. Al poder reemplazar los iones que funcionan como cofactores importantes, las enzimas como la superóxido-dismutasa (SOD) y la catalasa (CAT) también pueden ser inactivadas por este metal (Flora, Gupta \& Tiwari, 2012).

Aunque el peso molecular del $\mathrm{Pb}$ es mayor que el del Calcio, el Zinc y el Hierro, al tener la misma valencia química que éstos, puede mimetizarse fácilmente (Godwin, 2001; Patocka \& Cerny, 2003), al ser transportado y almacenado en las células a través de las distintas rutas metabólicas dependientes de los iones metálicos anteriormente mencionados. Esto facilita la modificación de los procesos de plegamiento proteico en el retículo endoplasmático (Patocka \& Cerny, 2003; Corsetti, Romano, Stacchiotti, Pasini \& Dioguardi, 2016), además de incrementar la formación de los radicales libres en la cadena respiratoria de la mitocondria (Kaur, Singh, Batish \& Kohli, 2012; Sousa \& Soares, 2014), así como la formación de cuerpos de inclusión citosólicos y nucleares (Zuo, Qu, Cooper, Goyer, Diwan \& Waalkes, 2009; Kaur et al., 2012); también provoca alteraciones en la reparación del DNA y la acetilación de las histonas en el núcleo (Gadhia, Calabro \& Barile, 2012; Xu et al., 2015), lo que explica su capacidad para afectar la salud y el estado REDOX celular (Figura 2).

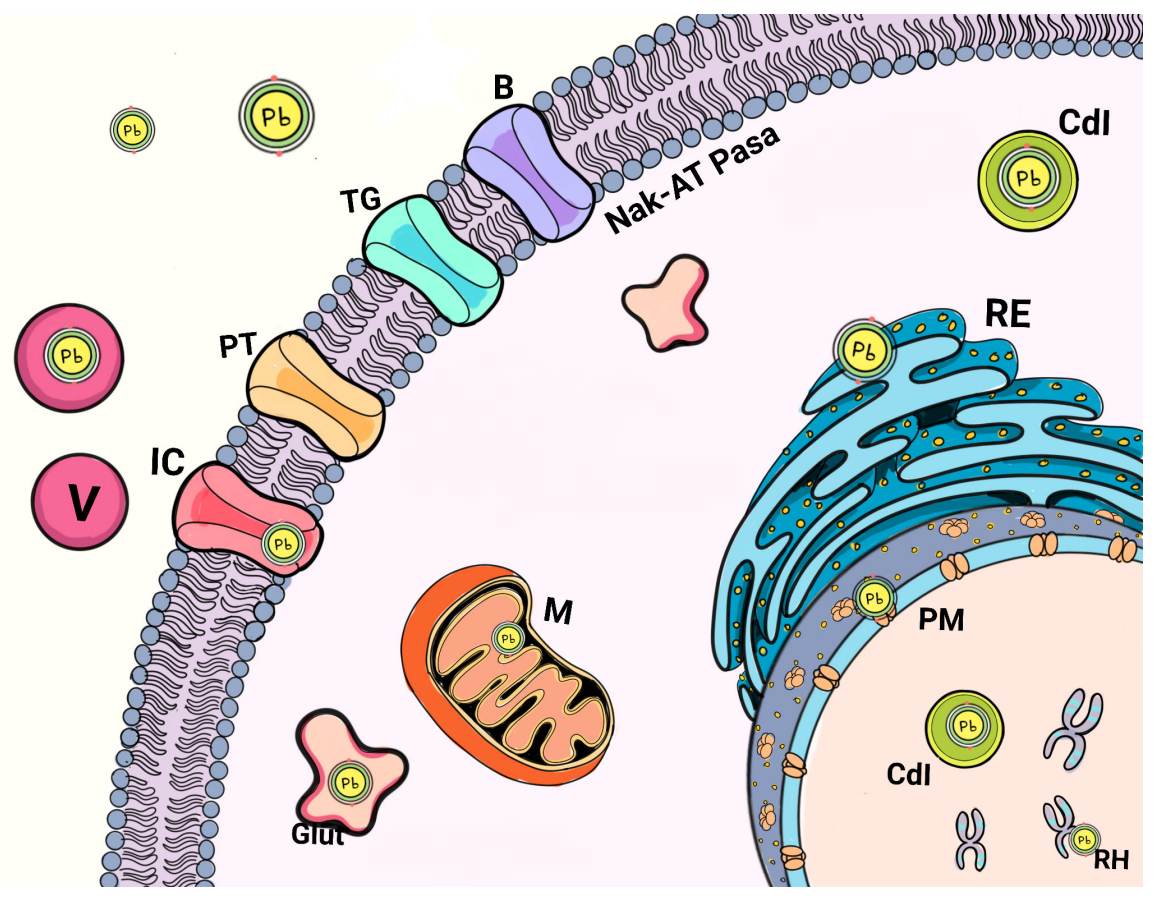

Figura 2. Compartimentos celulares en los que el Pb se ha encontrado anclado o afectando funciones importantes. V-vesículas, IC-canales iónicos, PT-proteínas transmembranales, TG-Transportadores del Glutatión, B-bombas y proteínas como la NaKATPasa, CdI-cuerpos de inclusión, Glut-Glutatión, M-mitocondria, RE-retículo endoplásmico, PM-proteínas membranales nucleares y RH-residuos aminoacídicos de histonas. Elaboración personal. 


\section{Acumulación del Pb en ovarios y sus efectos deletéreos en la salud reproductora}

Taupeau, Poupon, Nome \& Lefevre (2001), observaron en ratones que el $\mathrm{Pb}(10 \mathrm{ppm})$ no modifica el peso ovárico, pero sí puede acumularse en el ovario. Esto provoca la disminución en la cantidad de folículos primordiales saludables, incrementa el número de folículos atrésicos, la separación de células de la granulosa, y el reinicio de la meiosis en ovocitos degenerados, incluso a bajos niveles de $\mathrm{Pb}$ en la sangre. Si bien la intoxicación por el $\mathrm{Pb}$ no causa esterilidad total, compromete la fertilidad femenina al impedir la foliculogénesis (Lefevre, 2001), así como el desarrollo de las células germinales durante la organogénesis en la vida fetal (Taupeau et al., 2001; Lefevre, 2001; Fortune, 2003; Shah et al., 2008). Aunado a esto, en experimentos posteriores con crías de ratas expuestas in utero al $\mathrm{Pb}(0.05$, 0.1 y $0.15 \mathrm{ppm}$ ) hasta su nacimiento, se reportó dispersión de las células foliculares, destrucción del parénquima ovárico (Dumitrescu, Trif, Argherie \& Romeo-Teodor, 2009), así como una reducción en la cantidad de folículos en crecimiento (Shirota et al., 2003). Posteriormente, Ma et al. (2020), confirmaron que los efectos deletéros del $\mathrm{Pb}$ sobre el sistema reproductor observados en otras especies, son similares a los encontrados en gallinas expuestas a distintas concentraciones $(3.2,33.2,63.2 \mathrm{y}$ $93.2 \mathrm{ppm})$. Estos fueron tangibles desde la concentración más baja, mostrando una correlación significativa entre el aumento de la concentración administrada con la acumulación del $\mathrm{Pb}$ en el ovario, el incremento en la muerte celular, así como con la disminución en las actividades CAT, SOD, GR y glutatión, (Ma et al., 2020).

Bruno-Nascimento, Ezequiel-Risso \& Reis-Martinez (2016) expusieron a hembras de rata adultas a $2 \mathrm{ppm}$ de $\mathrm{Pb}$ a través del alimento, así como a las crías desde su gestación hasta la adultez. En la primera generación, el $\mathrm{Pb}$ fue encontrado principalmente en los huesos, seguido por el hígado y el riñón, así como en la leche materna. En la segunda generación y conforme incrementó la edad, la concentración acumulada fue mayor en el tejido óseo, además de los ovarios, provocando infertilidad. Debido a que el $\mathrm{Pb}$ puede atravesar la barrera placentaria, los animales estuvieron expuestos desde el útero. Posterior al nacimiento, la exposición al $\mathrm{Pb}$ continuó a través de la leche materna, provocando efectos deletéreos a la salud reproductora de la descendencia. Los autores enfatizan esto, ya que evidencia las graves consecuencias que sufrirán las futuras generaciones (Bruno-Nascimento et al., 2016; Dursun et al., 2016).

Por otra parte, Canaz, Kilinc, Sayar, Kiran \& Osyurek (2017), compararon las concentraciones del $\mathrm{Pb}$ y otros metales en distintos cultivos de muestras de tejido ovárico no neoplásico, de cáncer epitelial ovárico y de tumor epitelial limítrofe de distintas pacientes. Las concentraciones del $\mathrm{Pb}$ fueron 8 veces mayores en tejidos de tumores malignos y limítrofes (4.93 ppm) en comparación con los de ovarios saludables (0.62 ppm), existiendo una asociación entre la acumulación del metal con la proliferación celular en la superficie del epitelio cancerígeno, impidiendo a su vez la separación de las cromátidas hermanas durante la división celular (Rabanni-Chadegani, Abdosamadi, Fani. \& Mohammadian, 2009), y provocando el aumento de los radicales libres que dañan directamente al DNA(Jomova \& Valko, 2011). Esto último modifica y/o inactiva a las proteínas encargadas de la reparación de daños al material genético, lo que en las gónadas promoverá finalmente el desarrollo de procesos cancerígenos (Rabanni-Chadegani et al., 2009; Gadhia et al., 2012). Por esta razón los marcadores moleculares del estrés oxidante (SOD, CAT, Glut, entre otros) son una herramienta crucial al momento de identificar, dar seguimiento y encontrar soluciones a los daños ocasionados por la exposición al $\mathrm{Pb}$ (Ma et al., 2020).

\section{Efectos a nivel molecular del Pb en los ovarios}

$\mathrm{El} \mathrm{Pb}$ interfiere en la regulación hormonal femenina a través de la generación excesiva de los radicales libres (Ahamed \& Siddiqui, 2007), al provocar estrés oxidante que afecta a lípidos, proteínas y al DNA. Estas alteraciones pueden modificar la maduración folicular, así como el desarrollo de los órganos reproductores en etapas tempranas del desarrollo del embrión al interferir en los procesos de señalización hormonal (Dennery, 2004). De acuerdo con la ATSDR (2011), la exposición a concentraciones inferiores a los valores diarios tolerables o aceptables establecidos (ADI- Acceptable Dietary Intake por sus siglas en inglés) de metales tóxicos, podría afectar la salud reproductora de las mujeres. Debido a la gran variedad de los procesos llevados a cabo en el mantenimiento de la homeostasis en el ovario, los marcadores moleculares son herramientas confiables para evaluar los efectos adversos de la exposición al $\mathrm{Pb}$.

La modificación de los factores que intervienen en la modulación de los niveles hormonales afecta de manera importante la homeostasis ovárica. Por ejemplo, al cultivar células ováricas humanas con acetato de $\mathrm{Pb}(10 \mu \mathrm{M})$, se observó una reducción del $65 \%$ de la enzima P450 aromatasa (clave para la síntesis del estradiol en células de la granulosa) y del $25 \%$ del receptor de estrógenos $(\operatorname{Er} \beta)$ (Taupeau et al., 2003), así como una alteración en la interacción de los receptores de la FSH y la LH (Priya, Pillai \& Gupta, 2004). Este fenómeno también se ha observado en la exposición materna de las ratas al $\mathrm{Pb}(1 \mathrm{~mL}$ de 1,200 ppm), con una reducción del 50\% de la actividad de la proteína StAR (proteína reguladora aguda esteroidogénica, clave para la esteroidogénesis gonadal) que en el ovario de las crías se relacionó directamente con la disminución del estradiol (importante en los procesos de maduración folicular) (Srivastava et al., 2004), y también con la disminución en los niveles de la FSH y la LH en suero (Krieg, 2007). La señalización hormonal juega un papel importante en el mantenimiento de la salud reproductora, por lo que el daño causado sobre los tejidos no se limita al nivel estructural, sino que también compromete distintas vías metabólicas mediadas por las hormonas, esenciales para la 
correcta producción de los gametos femeninos (Nampoothiri \& Gupta, 2005; Nampoothiri, Agarwal \& Gupta, 2007).

Como se mencionó, el estado REDOX celular necesita ser regulado constantemente. Algunos de los elementos importantes para llevar esto a cabo son las proteínas reguladoras de la respuesta antioxidante (el factor de transcripción, Nrf2 o Factor 2 relacionado con el factor nuclear eritroide 2) y de la supervivencia celular ( NFk $\beta$, factor nuclear potenciador de la cadena ligera kappa de las células B activadas). Aglan et al. (2020) observaron una disminución significativa de éstas proteínas, independientemente de la concentración del $\mathrm{Pb}$ a la que los cultivos de células de la granulosa bovinas fueron expuestos (1, 2, 3, 5 y 10 ppm). Por otra parte, Ma et al. (2020) reportaron una correlación directa de la concentración del $\mathrm{Pb}$ con la muerte celular, así como con la inhibición de las enzimas SOD, GPx, CAT, GR y de la molécula del glutatión, que son importantes en el mantenimiento del estado REDOX ovárico. Lo anterior invariablemente comprometerá a la célula, por lo que la citotoxicidad, el estrés oxidante y la inhibición de las proteínas por la exposición al $\mathrm{Pb}$ no son efectos excluyentes entre sí, sino distintos resultados de las alteraciones inducidas por el metal.

La detección temprana de la alteración de la expresión de estos marcadores moleculares evidencia la vulnerabilidad de la homeostasis en las gónadas femeninas. Si bien estos trabajos no son tan frecuentes como aquellos enfocados en el análisis histológico, nos ayudan a entender el origen de las alteraciones que se traducirán en muerte celulary, por lo tanto, en patologías observadas en los estudios histológicos en los ovarios de organismos expuestos al $\mathrm{Pb}$.

\section{Efectos del $\mathrm{Pb}$ a nivel histológico en el ovario}

Las características histológicas del ovario saludable son resultado del balance de distintos procesos metabólicos que mantienen las funciones y estructuras celulares en óptimas condiciones. Durante la etapa reproductora, los ovarios presentan cambios estructurales y funcionales de manera cíclica, como el crecimiento y la maduración folicular, la ovulación, la formación y la degeneración del cuerpo lúteo. El mantenimiento adecuado de las estructuras involucradas en estos procesos influirá directamente en la capacidad reproductora femenina (Sharma, Garu \& Panwar, 2012a).

Junaid et al. (2010) evaluaron las características de los folículos presentes en el ovario de ratones adultos posterior a la exposición con distintas concentraciones de $\mathrm{Pb}(0,2,4$ y 8 ppm). El grupo expuesto a la menor dosis mostró una reducción significativa en los folículos primarios y secundarios en comparación con el grupo control (o testigo), los grupos expuestos a una dosis más alta mostraron una mayor reducción. Los folículos terciarios sufrieron un daño significativo sólo en las mayores concentraciones, sin embargo, en todos se observó atresia folicular. Sharma, Qureshi, Mogra \& Panwar (2012b) también reportaron atresia en ovarios de ratas hembra expuestas crónicamente al $\mathrm{Pb}$ (60 y 640 ppm). Al igual que Dhir \& Dhand (2010) quienes observaron el mismo fenómeno, sin embargo, no lograron esclarecer si la reducción en la cantidad de folículos observada era el resultado del daño en la reserva de los folículos primarios o del efecto directo sobre los folículos secundarios y terciarios.

Siguiendo con esta línea de investigación, Panwar, Sharma, Mogra, Qureshi \& Barber (2011) observaron que la administración de $\mathrm{Pb}$ ( $1 \mathrm{~mL}$ con 1200 ppm diario) a ratones hembra durante la gestación redujo la cantidad de folículos primordiales observables y alteró la estructura ovárica. La exposición durante la lactancia también dio lugar a la modificación de la estructura folicular, así como a la reducción en el número de folículos en desarrollo. Las crías sufrieron daños significativamente mayores en los ovarios en función del tiempo de exposición, entre ellos: reducción del número de folículos en distintos estadios, ovocitos dañados y en algunos casos completamente destruidos, además de una mayor cantidad de folículos atrésicos (Taupeau et al., 2001); así como la alteración total en la estructura de las células de la granulosa, y disminución de sus capas (Panwar et al., 2011).

De manera similar, Sharma et al. (2012 a) trabajaron con ratones expuestos al acetato de plomo ( $\mathrm{PbA})(1 \mathrm{~mL}$ con $640 \mathrm{ppm}$ diario a hembras gestantes) desde la gestación hasta los 21 días post destete. Los ovarios de las crías sacrificadas en etapas tempranas presentaron una menor cantidad de folículos primordiales, con estructura alterada, aumento de la atresia folicular, así como algunos folículos con el ovocito completamente destruido; estos parámetros se exacerbaron después de 21 días de exposición. Debido a que el $\mathrm{Pb}$ puede traspasar la barrera placentaria $\mathrm{y}$ afectar al tejido fetal, se infiere a partir de estos trabajos que la exposición al metal en etapas de vida temprana modifica a los precursores básicos gonadales, causando una drástica reducción de la fertilidad durante la edad adulta.

Como se mencionó anteriormente, las ERO tienen la capacidad de dañar los componentes histológicos mediante la modificación de proteínas importantes para el mantenimiento de las estructuras celulares (Agarwal et al., 2016). Sharma et al. (2012 b) formaron grupos de ratones hembra expuestas al acetato de $\mathrm{Pb}$ (50 ppm) y a las vitaminas $\mathrm{C}, \mathrm{E}$ o $\mathrm{C}+\mathrm{E}$, conocidas por actuar de manera sinérgica en el sistema AOX del organismo. El grupo tratado con $\mathrm{Pb}$ presentó daño evidente en los folículos y en el epitelio germinal. Las hembras expuestas y tratadas con vitaminas $\mathrm{C}$ $\mathrm{y}$ vitaminas $\mathrm{C}+\mathrm{E}$ tuvieron una protección leve contra el efecto del $\mathrm{Pb}$. En el grupo tratado sólo con vitamina $\mathrm{E}$ los ovarios estuvieron mejor protegidos. En este trabajo se demostró que el $\mathrm{Pb}$ afecta los folículos en desarrollo y maduros, aumentando la magnitud del daño en función del tiempo de exposición. Previamente, Bedaiwy \& Falcone (2003) mencionaron que 
las ERO juegan un papel importante en la fisiología del eje hipotálamo-pituitario-gonadal, por tanto, el desbalance en estos niveles causará no sólo un daño histológico directo, si no que también se reflejará con modificaciones a nivel fisiológico.

Sharma \& Bhattacharya (2014) encontraron que en los ratones hembra expuestas al acetato de $\mathrm{Pb}(0.5 \mathrm{ppm})$ durante la lactancia (21 días posteriores al nacimiento), hubo una reducción en el diámetro y la cantidad de folículos en la fase de crecimiento, así como un incremento de los folículos antrales atrésicos, con daño progresivo conforme avanzaban los días de exposición. Bires, Maracek, Bartko, Biresova \& Weissova (1995), también habían observado estos efectos en recién nacidos, aunado a una reducción en el número de células germinales en las gónadas en desarrollo de ovejas expuestas al $\mathrm{PbA}$, mientras que Sharma \& Bhattacharya (2014) notaron además una deformación muy marcada del ovario en las hembras que consumieron leche materna contaminada. Finalmente, Taupeau et al. (2001) y Qureshi, Sharma \& Mogra(2010), plantean que las alteraciones visibles no se deben sólo a la exposición incidental, sino que el $\mathrm{Pb}$ acumulado en el ovario podría provocar una disfunción de la foliculogénesis.

Se ha demostrado que el $\mathrm{Pb}$ es uno de los tóxicos de mayor importancia a nivel reproductor, ya que incluso a bajas concentraciones, afecta la estructura y las funciones gonadales, causando alteraciones en la fertilidad (Qureshi \& Sharma, 2012). Dumitrescu et al. (2015) evaluaron la acumulación del Pb, así como la vulnerabilidad de las células ováricas, de las trompas de Falopio y del útero en hembras de rata Wistar maduras sexualmente expuestas a distintas concentraciones $(0.05,0.1$ y $0.15 \mathrm{ppm}$ ). Las ratas expuestas mostraron un incremento significativo en la concentración corporal del $\mathrm{Pb}$ en relación directa con el nivel de exposición (hasta 396\% más que el grupo control en la concentración más alta). Los niveles séricos de FSH, estradiol y progesterona disminuyeron, mientras que los de LH y testosterona se incrementaron, esto anteriormente comprobado por Dumitrescu, Cristina \& Muselin(2014). En todos los grupos, los principales cambios en los ovarios fueron edemas difusos, necrosis y reducción en el tamaño de los folículos (Shah et al., 2008). Dumitrescu et al. (2015) coinciden con estudios previos en que los efectos pueden deberse a la acción sobre la unidad estructural hipotálamo-hipofisiario o a la alteración de la síntesis esteroidea en las células de la granulosa. Estos factores, junto a la modificación de los componentes celulares por el aumento en la cantidad de radicales libres y el consecuente estrés oxidante, afectan el crecimiento y la maduración de los óvulos (Agarwal et al., 2016; Balasch \& Fabregues, 2006).

En un estudio realizado por Jasim-Sodani (2017), se evaluaron los efectos del $\mathrm{Pb}(0.3 \mathrm{ppm})$ sobre la salud reproductora de las hembras maduras de ratón durante 14 días. A pesar de que la cantidad de folículos no disminuyó significativamente, todos tenían ovocitos degradados, ovocitos con zona pelúcida no visible, degeneración en las células de la corona radiata y apoptosis masiva; las células de la granulosa se redujeron en número y se dispersaron, presentando picnosis nuclear. Los daños en los componentes celulares generan la muerte fisiológica del óvulo, provocando una infertilidad inmediata (Gupta, Singh, Singh \& Reddy, 2010).

Los efectos del $\mathrm{Pb}$ sobre el ovario anteriormente citados son de gran relevancia en temas de salud pública. Se ha comprobado que los niveles de éste son significativamente mayores en mujeres infértiles $(0.028$ a 0.017 ppm) en comparación con mujeres fértiles (0.012 ppm) (Cerna, Krskova, Ceichanova \& Snevackova, 2012; Hsiao-Ling et al., 2015) y, a pesar de encontrarse por debajo de los valores de referencia necesarios para considerarse un riesgo para la salud humana, las afecciones pueden ser a largo plazo (ATSDR, 2011). Los estudios abordados demuestran que la exposición ambiental al $\mathrm{Pb}$ sí provoca alteraciones en la fisiología e histología ovárica, así como en la capacidad reproductora en más de una generación de la población femenina.

\section{Conclusiones}

A través de los trabajos revisados se concluye que las gónadas femeninas cuentan con mecanismos de protección efectivos que resguardan de la pérdida de la homeostasis causada por la exposición al $\mathrm{Pb}$ durante períodos cortos, mientras que, de manera crónica aumenta el daño tanto estructural, como el de los procesos clave para mantener un ovario funcional y saludable. Este tipo de exposiciones, así como la liberación del Pb del sistema óseo durante la gestación y la lactancia, plantean un riesgo latente, ya que en algunas ocasiones no es fácilmente detectable. Aunado a la probabilidad de sufrir abortos, el bajo peso al nacer y las alteraciones en el desarrollo neurológico, además del daño a los componentes celulares del ovario causado por el $\mathrm{Pb}$ afectará negativamente a la descendencia.

La totalidad de los mecanismos involucrados en el daño a las gónadas por exposición al $\mathrm{Pb}$ es aún desconocida. El hecho de que su valencia química sea similar a la del Calcio y la del Zinc, así como su interacción con los grupos sulfhidrilo de distintas enzimas, confiere al $\mathrm{Pb}$ diversas vías por las que afecta a los ovarios. Debido a que el balance entre las ERO y los AOX es vital para la maduración folicular, el desarrollo de los órganos reproductores en etapas tempranas del embrión, así como para mantener la calidad del material genético heredado, los trabajos revisados sugieren que el desbalance en el estado REDOX provocado por el $\mathrm{Pb}$ es una de las vías principales por las que ejerce sus efectos sobre la histoarquitectura ovárica, así como en los procesos fisiológicos relacionados al desarrollo y maduración folicular.

Las concentraciones del $\mathrm{Pb}$ empleadas en los trabajos experimentales suelen ser mucho mayores que aquellas observadas en la vida real, dado que se han enfocado 
principalmente en explicar los mecanismos de daño causados por el $\mathrm{Pb}$, más que en simular un escenario real, que haría difícil el estudio de estos mecanismos de daño en períodos cortos a bajas concentraciones tomando en cuenta la vida media de los modelos empleados. Los estudios in vitro han ayudado a comprender el modo en que las vías de señalización son afectadas durante la exposición al $\mathrm{Pb}$, y cómo ésto se evidencia a través de las alteraciones a nivel celular e histológico.

En más de una ocasión se ha demostrado que tanto las dosis como la respuesta de los estudios in vitro difieren de los estudios in vivo, en que el efecto se da en función de una respuesta sistémica. Aunado a esto, las concentraciones no siempre serán las mismas en la vida real. A pesar de estas limitantes, la posibilidad de realizar trabajos interdisciplinarios, así como revisiones más exhaustivas, podrá complementar el conocimiento que se tiene hasta ahora, mejorando la comprensión de los mecanismos de acción del $\mathrm{Pb}$ en el ovario, así como del riesgo que representa para la salud reproductora de la población femenina.

\section{Agradecimientos}

Selene Karinna Trujillo-Vázquez es estudiante del Doctorado en Ciencias Biológicas y de la Salud en la Universidad Autónoma Metropolitana, Ciudad de México. Cuenta con el apoyo 637165 del CONACYT, México.

Agradecemos al Dr, Jorge Castañeda Sánchez, Coordinador del programa de Posgrado en Ciencias Biológicas y de la Salud, así como al Consejo Nacional de Ciencia y Tecnología (CONACYT), el apoyo otorgado a la alumna en su formación a lo largo de sus estudios.

\section{REFERENCIAS}

Agarwal,A., Gupta, S. \& Sharma, R. K. (2015). Role of oxidative stress in female reproduction. Reproductive Biology and Endocrinology, 3(28), 1-21. https://doi.org/10.1186/14777827-3-28

Aglan, H. S., Gebremedhn, S., Salilew-Wondim, D., Neuhof, C., Tholen, E., Holker, M., Schellander, K. \& Tesfayem, D. (2020). Regulation of Nrf2 and NF-kB during lead toxicity in bovine granulosa cells. Cell and Tissue Research, 380, 643-655. https://doi.org/10.1007/s00441-020-03177-x

Ahamed, M. \& Siddiqui, M. K. (2007). Low level lead exposure and oxidative stress: current opinions. Clinica Chimica Acta, 383 (1-2), 57-64. https://doi.org/10.1016/j. cca.2007.04.024

ATSDR (Agency for Toxicy Substances and Disease Registry) (2011).Toxicological Profile of Lead. Disponible en: https:// www.atsdr.cdc.gov/toxprofiles/tp13.pdf. Acceso el 28/ Agosto/2017

Balasch, J. \& Fabregues, F. (2006). LH in the follicular phase: neither too high nor too low. Reproductive Biomedicine Online, 12, 406-415. https://doi.org/10.1016/s14726483(10)61991-8
Bedaiwy, M. A. \& Falcone, T. (2003). Peritoneal fluid environment in endometriosis. Clinicopathological implications. Minerva Ginecolgica, 55, 333-345. https:// clevelandclinic.org/reproductiveresearchcenter/docs/ faltdoc049.pdf

Behrman, H. R., Kodaman, P.H., Preston, S. L. \& Gao, S. (2001). Oxidative stress and the ovary. Reproductive Sciences, $\mathbf{8}$, 40-41.https://doi.org/10.1177\%2F1071557601008001S13

Beyersmann, D., \& Hartwig, A. (2008). Carcinogenic metal compounds: recent insight into molecular and celular mechanisms. Archives of Toxicology, 82 (8), 493-512. https://doi.org/10.1007/s00204-008-0313-y

Bindler, R. (2011). Contaminated lead environments of man: Reviewing the lead isotopic evidence in sediments, peat, and soils for the temporal and spatial patterns of atmospheric lead pollution in Sweden. Environmental Geochemistry and Health, 33, 311-329. https://doi.org/10.1007/s10653011-9381-7

Bires, J., Maracek, I., Bartko, P., Biresova, M. \& Weissova, T. (1995). Accumulation of trace elements in sheep and the effects upon qualitative and quantitative ovarian changes. Veterinary and Human Toxicology, 37, 349 -356. https:// pubmed.ncbi.nlm.nih.gov/8540227/

Bloom, M. M., Louis, G. M., Sundaram, R., Kostyniak, P. J. \& Jain, J. (2011). Associations between blood metals and fecundity among women residing in New York State. Reproductive Toxicology, 31 (2), 158-163. https://www.sciencedirect.com/science/article/abs/ pii/S0890623810003102?via\%3Dihub, https://doi. org/10.1016/j.reprotox.2010.09.013

Bruno-Nascimento, C. R., Ezequiel-Risso, W. \& ReisMartinez, C. B. (2016). Lead accumulation and metallothionein contente in female rats of different ages and generations after daily intake of $\mathrm{Pb}$-contaminated food. Environmental Toxicology and Pharmacology, 48, 272-277. https://www.sciencedirect.com/science/article/ pii/S138266891630285X, https://doi.org/10.1016/j. etap.2016.11.001

Canaz, E., Kilinc, M., Sayar, H., Kiran, G. \& Osyurek, E. (2017). Lead, selenium and nickel concentrations in epitelial ovarian cancer, borderline ovarian tumor and healthy ovarian tissues. Journal of Trace Elements in Medicine and Biology, 43, 217-223. https://doi.org/10.1016/j.jtemb.2017.05.003

Caravanos, J., Dowling, R., Téllez-Rojo, M., Cantoral, A., Kobrosly, R., Estrada, D., Orjuela, M., Gualtero, S., Ericson, B., Rivera, A. \& Fuller, R. (2014). Blood lead levels in Mexico and pediatric burden of disease implications. Annals of Global Health, 80 (4), 269-277. https://pubmed. ncbi.nlm.nih.gov/25459328/, https://doi.org/10.1016/j. aogh.2014.08.002

CDC (Center for Disease Control and Prevention) (2010). Guidelines for the identification and management of lead exposure in pregnant and lactating women. US Department of Health and Human Services. 
Cerna, M., Krskova, A., Ceichanova, M. \& Snevackova, V. (2012). Human biomonitoring in the Czech Republic: an overview. International Journal of Hygiene and Environmental Health, 215 (2), 109-119. https://sciarium. com/file/212486/, DOI 10.1016/j.ijheh.2011.09.007

Chang, S. H., Cheng, B. H., Lee, S. L., Chuang, H. Y., Yang, C. Y., Sung, F. C. \& Wu, T. N. (2006). Low blood lead concentration in association with infertility in women. Environmental Research, 101, 380-386. https:/www.sciencedirect.com/ science/article/abs/pii/S0013935105001490?via\%3Dihub, https://doi.org/10.1016/j.envres.2005.10.004

Chiu, T. T \& Yang, D. M. (2012). Intracellular $\mathrm{Pb}^{2+}$ content monitoring using a protein-based $\mathrm{Pb}^{2+}$ indicator. Toxicological Sciences, 126(2), 436-445.https://academic. oup.com/toxsci/article/126/2/436/1690529, https://doi. org/10.1093/toxsci/kfs007

Corsetti, G., Romano, C., Stacchiotti,A., Pasini, E. \& Dioguardi F.S. (2017). Endoplasmic reticulum stress and apoptosis triggered by sub-chronic lead exposure in mice spleen: a Histopathological Study. Biological Trace Element Research, 178, 86-97. https://doi.org/10.1007/s12011016-0912-z

Dennery, P. A. (2004). Role of Redox in fetal development and neonatal diseases. Antioxidants \& Redox Signaling, 6 (1), 147-153. https://doi.org/10.1089/152308604771978453

Dhir, V. \& Dhand, P. (2010). Toxicological approach in chronic exposure to lead on reproductive functions in female rats. Toxicology International, 17, 1-7. https:/europepmc. org/article/PMC/2964744, https://doi.org/10.4103/09716580.68340

Doumouchtsis, K. K., Doumouchtsis, S. K., Doumouchtsis, E. K. \& Perrea, D. N. (2009). The effect of lead intoxication on endocrine functions. Journal of Endocrinological Investigation, 32, 175-183. https://pubmed.ncbi.nlm.nih. gov/19411819/, https://doi.org/10.1007/bf03345710

Dumitrescu, E., Triff, A., Argherie, D. \& Romeo-Teodor, C. (2009). The consequences in utero exposure to lead acetate on exposure and integrity biomarkers of reproductive system in female rats. Medicina veterinara, 2, 295-300.

Dumitrescu,E., Cristina, R. T.\&Muselin, F.(2014). Reproductive biology study of dynamics of female sexual hormones: a 12-month exposure to lead acetate rat model. Turkish Journal ofBiology, 38, 581-585. https:/www.researchgate. net/publication/265058040_Reproductive_biology_ study_of_dynamics_of_female_sexual_hormones_A_12month_exposure_to_lead_acetate_rat_model,http://dx.doi. org/10.3906/biy-1402-50

Dumitrescu, E., Chiurciu, V., Florin, M., Popescu, R., Brezovan, D. \& Cristina, R. T. (2015). Effects of long-term exposure of female rats to low levels of lead: ovary and uterus histological architecture changes. Turkish Journal of Biology, 39, 284289. https://www.semanticscholar.org/paper/Effects-oflong-term-exposure-of-female-rats-to-low-Dumitrescu-
Chiurciu/d8cab36dc3067f3dd25cbf156b2f450a0b040c89, https://doi.org/10.3906/BIY-1407-6

Dursun, A., Yurdakok, K., Yalcin, S. S., Tekinalp, G., Aykut, O., Orhan, G. \& Morgil, G. K. (2016). Maternal risk factors associated with lead, mercury and cadmiun levels in umbilical cord blood, breast milk and newborn hair. The Journal of Maternal-Fetal \& Neonatal Medicine, 29, 954-961.https://doi.org/10.3109/14767058.2015.1026255

Fitamo, D., Itana, F. \& Olsson, M. (2007). Total contents and sequential extraction of heavy metals in soils irrigated with wastewater, Akaki, Ethiopia. Environmental Management, 39 (2), 178-193. https://doi.org/10.1007/s00267-0060074-4

Flora, G., Gupta, D. \& Tiwari, A. (2012). Toxicity of lead: A review with recent updates. Interdisciplinary Toxicology, 5 (2), 47-58. https://doi.org/10.2478/v10102-012-0009-2

Fortune, J.E.(2003). The early stages of follicular development: activation of primordial follicles and growth of preantral follicles. Animal Reproduction Science, 78, 135-163. https://pubmed.ncbi.nlm.nih.gov/12818642/, https://doi. org/10.1016/s0378-4320(03)00088-5

Fuentes-Gandara, F., Pinedo-Hernández, J., Marrugo-Negrete, J. \& Díez, S. (2016). Human health impacts of exposure to metals through extreme consumption of fish from the Colombian Caribbean Sea. Environmental Geochemistry and Health, 40, 229-242. https://doi.org/10.1007/s10653016-9896-z

Gadhia, S. R., Calabro, A. R. \& Barile, F. A. (2012). Trace metals alter DNA repair and histone modification pathways concurrently in mouse embryonic stem cells. Toxicology Letters, 212 (2), 169-179. https://www.sciencedirect.com/ science/article/abs/pii/S0378427412011290, https://doi. org/10.1016/j.toxlet.2012.05.013

Godwin, H.A. (2001). The biological chemistry oflead. Elsevier Science, 5 (2), 223-227. https://www.sciencedirect.com/ science/article/abs/pii/S1367593100001940, https:/doi. org/10.1016/S1367-5931(00)00194-0

Gonick, H. C. (2011). Lead-Binding Proteins: AReview. Journal of Toxicology, 1, 1-10. https://doi.org/10.1155/2011/686050

Gulson, B. L., Mizon, K. J., Korsch, M. J., Palmer, J. M. \& Donnelly, J.B. (2003). Mobilization of lead from human bone tissue during pregnancy and lactation: a summary of long-term research. Science of the Total Environment, 303, 79-104.https://www.sciencedirect.com/science/article/abs/ pii/S0048969702003558, https://doi.org/10.1016/S00489697(02)00355-8

Gupta N., Singh, G., Singh S. M. \& Reddy, K. R. (2010). Histological changes in ovaries of mice exposed to Butea monosperma preliminary study. International Journal of Morphology, 28 (4),1309-1314. https://www. semanticscholar.org/paper/Histological-Changes-inOvaries-of-Mice-Exposed-to-Gupta-Singh/26758cf06f4f0 16a2088a74729bd438db824e153, https://doi.org/10.4067/ S0717-95022010000400051 
Hayashi, K., Miyamoto, A., Konari, A., Ohtani, M. \& Fukui, Y. (2003). Effect of local interaction of reactive oxygen species with prostanglandin $\mathrm{F}_{2 \alpha}$ on the release of progesterone in ovine corpora lutea in vivo. Theriogenology, 59, 13351344. https://www.sciencedirect.com/science/article/abs/ pii/S0093691X02011731, https://doi.org/10.1016/S0093691X(02)01173-1

Hobi, M. H. (2014). The Pollution of lead (Pb) in the Soil of Baghdad City after 2003. International Journal of Engineering and Technical Research. 3 (4), 201-206.

Hoyer, P. B. (2014). Ovarian toxicology. Editorial CRC Press. $2^{\mathrm{a}}$ Edición. Nueva York, Estados Unidos. 371pp

Hsiao-Ling, L., Hsiao-Jui, W., Hsin-Yi, H., Kai-Wei, L. \& Ling-Chu, C. (2015). Relationship between risk factors for infertility in women and lead, cadmium and arsenic blood levels: a cross-sectional study from Taiwan. BMC Public Health, 15, 1220. https://doi.org/10.1186/s12889015-2564-x

Iqbal, M.P.(2012). Lead pollution: a risk factor for cardiovascular disease in Asian developing countries. Cardiovascular Diseases Commons, 25, 289-94.

Jarvis, P., Quy, K., Macadam, J., Edwards, M. \& Smith, M. (2018). Intake of lead $(\mathrm{Pb})$ from tap water of homes with leaded and low lead plumbing systems. Science of the Total Environment, 644 (10), 1346-1356. https://pubmed. ncbi.nlm.nih.gov/30743847/, https://doi.org/10.1016/j. scitotenv.2018.07.064

Jasim-Sodani, I. (2017). Study the adverse effects of exposure to lead acetate on mice ovarian tissue. International Journal of Advanced Research, 5 (5), 727-735.

Jomova, K. \& Valko, M. (2011). Advances in metal-induced oxidative stress and human disease. Toxicology, 283 (2-3), 65-87. https://doi.org/10.1016/j.tox.2011.03.001

Junaid, M., Chowdhury, D.K., Narayan, R., Shanke, R. \& Saxena, D.K. (2010). Lead induced changes in ovarian folicular development and maturation in mice. Journal of Toxicology and Environmental Health, 50, 31-40. https:// doi.org/10.1080/009841097160582

Kaur, G., Singh, H.P., Batish, D.R. \& Kohli, R.K. (2012). Lead $(\mathrm{Pb})$-induced biochemical and ultrastructural changes in wheat (Triticum aestivum) roots. Protoplasma, 250, 53-62. https://doi.org/10.1007/s00709-011-0372-4

Kirberger, M., Wong, H.C., Jiang, J. \& Yang, Y. (2013). Metal toxicity and opportunistic binding of $\mathrm{Pb}^{2+}$ in proteins. Journal of Inorganic Chemistry, 1, 1-44. https://academic. oup.com/endo/article/151/1/7/2456018, https://doi. org/10.1210/en.2009-0916

Kovacs, C.S.(2001). Calcium and bone metabolism in pregnancy and lactation. The Journal of Clinical Endocrinology and Metabolism, 86 (6), 2344-2348. https://pubmed.ncbi.nlm. nih.gov/11397820/,https://doi.org/10.1210/jcem.86.6.7575

Krieg Jr,E. F. (2007). The relationships between blood lead levels and serum follicle stimulating hormone and luteinizing hormone in the third National Health and Nutrition
Examination Survey. Environmental Research, 104 (3), 374-382. https://doi.org/10.1016/j.envres.2006.09.009

Lefevre B. (2001). Lead accumulation in the mouse ovary after treatment-induced follicular atresia. Reproductive Toxicology, 15, 385-439. https:/www.sciencedirect.com/ science/article/abs/pii/S0890623801001393, https://doi. org/10.1016/S0890-6238(01)00139-3

Liu, Y., Huo, X., Xu, L., Wei, X., Wu, W., Wu, X. \& Xu. (2018). Hearing loss in children with e-waste lead and cadmium exposure. Science of the Total Environment, 624, 621-627. https://doi.org/10.1016/j.scitotenv.2017.12.091

Luo, J., Meng, J, Ye, Y., Wang, Y. \& Bai, L. (2016). Population health risk via dietary exposure to trace elements $(\mathrm{Cu}$, $\mathrm{Zn}, \mathrm{Pb}, \mathrm{Cd}, \mathrm{Hg}$, and As) in Qiqihar, Northeastern China. Environmental Geochemistry and Health, 40, 217-227. https://doi.org/10.1007/s10653-016-9895-0

Ma, Y., Shi, Y. S., Wu, Q. J., Wang, Y. Q., Wang, J. P. \& Liu, Z. H. (2020). Effects of varying dietary intoxication with lead on the performance and ovaries of laying hens. Poultry Science, 99 (9): 4505-4513. https:/www.sciencedirect. com/science/article/pii/S0032579120303771, https://doi. org/10.1016/j.psj.2020.06.015

Mah, V. \& Jalilehvand, F. (2013). Lead (II) Complex Formation with Glutathione. Inorganic Chemistry, 51 (11), 6285-6298. https://doi.org/10.1021/ic300496t

Maloney B., Bayon B.L., Zaqia H.N. \& Lahiri, D.L. (2018). Latent consequences of early-life lead $(\mathrm{Pb})$ exposure and the future: Addressing the Pb Crisis. Neurotoxicology, 68 (1), 126-132. https://doi.org/10.1016/j.neuro.2018.06.016

Martínez-Riera, N., Sant-Yacumo, R. A., Riera de MartínezVilla, N. (2001). Efectos de la exposición a bajas concentraciones de plomo en ratones sobre diferentes parámetros bioquímicos. Revista de Toxicología, 18, 82-86.

Masudul-Hoque, M. S.A., Umehara, T., Kawai, T. \& Shimada, M. (2021).Adverse effect of superoxide-induced mitochondrial damage in granulosa cells on follicular development in mouse ovaries. Free radicalbiology and Medicine, 163, 344355.https://doi.org/10.1016/j.freeradbiomed.2020.12.434

Matthews, S.G. \& Phillips, D.I.W. (2010). Transgenerational inheritance of the stress response: A new frontier in stress research. Endocrinology, 151, 7-13. https://academic. oup.com/endo/article/151/1/7/2456018, https://doi. org/10.1210/en.2009-0916

Nampoothiri, L.P. \& Gupta, S. (2005). Simultaneous effect of lead and cadmium on granulosa cells: A cellular model for ovarian toxicity. Reproductive Toxicology, 21(2), 179-185. https://doi.org/10.1016/j.reprotox.2005.07.010

Nampoothiri, L.P. \& Gupta, S. (2008). Biochemical Effects of Gestational Coexposure to Lead and Cadmium on reproductive performance, placenta, and ovary. Journal of Biochemical and Molecular Toxicology, 22 (5), 337-344. https://doi.org/10.1002/jbt.20246

Nampoothiri, L.P., Agarwal, A. \& Gupta, S. (2007). Effect of coexposure to lead and cadmium on antioxidant status in 
rat ovarian granulose cells. Archives of Toxicology, 81, 145-150. https://doi.org/10.1007/s00204-006-0133-X

Nazarpour, A., Watts, M.J., Madhani, A. \& Elahi, S. (2019). Source, spatial distribution and pollution assessment of $\mathrm{Pb}, \mathrm{Zn}$, and $\mathrm{Pb}$ isotopes in urban soils of Ahvaz City, a semi-arid metropolis in southwest Iran. Science Reports, 9 , 5349-5359. https://doi.org/10.1038/s41598-019-41787-w

Ngole-Jeme, V.M., Ekosse, G.I. \& Songca, S.P. (2018). An analysis of human exposure to trace elements from deliberate soil ingestion and associated health risks. Journal of Exposure Science \& Environmental Epidemiology, 28, 55-63. https://doi.org/10.1038/jes.2016.67

Oben-Gyasi, E. (2019). Sources of lead exposure in various countries. Reviews on Environmental Health, 34 (1), 25-34. https://doi.org/10.1515/reveh-2018-0037

Ospina, I.D. (2015). Ficha Técnica: Acetato de Plomo Tri Hidratado. Distribuidora de Químicos Industriales 5pp: https://dqisa.com/wp-content/uploads/2015/10/ ACETATO-DE-PLOMO.pdf revisado el 08/Febrero/2019).

Paksy, K., Gati, I., Naray, M. \& Rajczy, K. (2001). Lead accumulation in human ovarian follicular fluid, and in vitro effect of lead on progesterone production by cultured human ovarian granulosa cells. Journal of Toxicology and Environmental Health, Part A, 62, 359366. https://pubmed.ncbi.nlm.nih.gov/11261898/, https:// doi.org/10.1080/152873901300018093

Panwar, K., Sharma, R., Mogra, S., Qureshi, N. \& Barber I. (2011). Effect of lead exposure during gestation and lactation on developing ovary in Swiss mice. Reproductive Toxicology, 6 (1), 14-20. https://www.sciencedirect.com/ science/article/abs/pii/S0890623802000370?via\%3Dihub, https://doi.org/10.1016/S0890-6238(02)00037-0

Patocka, J. \& Cerny K. (2003). Inorganic lead toxicology. Acta Medica. 46 (2), 65-72. https://www.semanticscholar.org/ paper/Inorganic-lead-toxicology.-Patocka-Cerny/04b5 4f81e1285494be384e04a840013a4abf4392, https://doi. org/10.14712/18059694.2019.8

Pelfrene, A. \& Douay, F. (2017). Assessment of oral and lung bioaccessibility of $\mathrm{Cd}$ and $\mathrm{Pb}$ from smelter-impacted dust. Environmental Science and Pollution Research, 25 (4), 3718-3730. https://doi.org/10.1007/s11356-017-0760-1

Priya, P.L., Pillai, A. \& Gupta, S. (2004). Effect of simultaneous exposure to lead and cadmium on gonadotropin binding and steroidogenesis on granulosa cells: An in vitro study. Indian Journal of Experimental Biology, 42, 143-148.

Qureshi, N. \& Sharma, R. (2012). Lead toxicity and infertility in female Swiss mice: A review. Journal of Chemical, Biological and Physical Sciences, 2 (4), 1849-61.

Qureshi, N., Sharma, R. \& Mogra, S. (2010). The microscopically examination of the ovary reveals that there was apparent damage and reduction in number of primordial follicles while number of atretic follicles increases markedly. Asian Journal of Environmental Sciences, 5, 44-48.

Rabanni-Chadegani, A., Abdosamadi, S., Fani, N. \&
Mohammadian, S. A. (2009). Comparison of the effect of lead nitrate on rat liver chromatin, DNA and histone proteins in solution. Archives of Toxicology, 83(6), 565-570. https:// doi.org/10.1007/s00204-008-0362-2

Richards, J. S. \& Pangas, S. A. (2010). The ovary: basic biology and clinical implications. Journal of Clinical Investigation, 120 (4), 963-972. http://doi.org/10.1172/JCI41350

Roy S. \& Edwards, M.A. (2019). Preventing another lead $(\mathrm{Pb})$ in drinking water crisis: Lessons from the Washington, D.C. and Flint MI contamination Events. Current Opinion in Environmental Science \& Health, 7, 34-44. https://www.sciencedirect.com/science/article/ abs/pii/S2468584418300424, https://doi.org/10.1016/j. coesh.2018.10.002

Schell, L. M., Burnitz, K. K. \& Lathrop, P. W. (2010). Pollution and human biology. Annals of Human Biology, 37, 347-366. https://doi.org/10.3109/03014461003705511

Shah, A. S., Shariff, M. M., Khan, S. A., Tayyab, M., Chaudary, N.A. \& Ahmed, N. (2008). Correlation of blood lead levels with atresia of ovarian follicles of albino mice. Annals of Pakistan Institute of Medical Sciences, 4, 188-192.

Sharma, R., Garu, U. \& Panwar, K. (2012a). Developing Gonads and Lead Exposure. World Journal of Environmental Biosciences, 1, 30-37.

Sharma, D. N. \& Bhattacharya, L. (2014). Effects of maternal lead acetate exposure during lactation on postnatal development of ovaries in offspring of swiss albino mice. International Journal of Plant, Animal and Environmental Sciences, 4 (2), 419-424.

Sharma, R., Qureshi, N., Mogra, S. \& Panwar, K. (2012b). Lead induced infertility in Swiss Mice and Role of Antioxidants. International Journal of Environmental Research, 2 (2), 72-82. https://web.archive.org/web/20180420230138id_ http://environmentaljournal.org/2-2/ujert-2-2-8.pdf

Shirota, M., Soda, S., Katoh, C., Asai, S., Sato, M., Ohta, R., Watanabe, G., Taya, K. \& Shirota, K. (2003). Effects of reduction of the number of primordial follicles on follicular development to achieve puberty in female rats. Reproduction, 125, 85-94. https://rep.bioscientifica.com/ view/journals/rep/125/1/85.xml, https://doi.org/10.1530/ rep. 0.1250085

Sousa, C. A. \& Soares, E. B. (2014). Mitochondria Are the Main Source and One of the Targets of Pb (Lead)-Induced Oxidative Stress in the Yeast Saccharomyces cerevisiae. Applied Microbiology and Biotechnology, 98 (11), 51535160. https://doi.org/10.1007/s00253-014-5631-9

Srivastava, V., Dearth, R. K., Hiney, J. K., Ramirez, L. M., Bratton, G. R. \& Les Dees, W. (2004). The effects of lowlevel $\mathrm{Pb}$ on steroidogenic acute regulatory protein (StAR) in the prepubertal rat ovary. Toxicological Sciences, 77, 35-40. https://doi.org/10.1093/toxsci/kfg249

Sugino, N. (2005). Reactive oxygen species in ovarian physiology. Reproductieve Medicine and Biology, 4, 31-44. https://doi.org/10.1111/j.1447-0578.2005.00086.x 
Tamayo y Ortiz, M., Téllez-Rojo, M. M., Hu, H., HernándezÁvila, M., Wright, R., Amarasiriwardena, C., Lupoli, N., Mercado-García, A., Pantic, I. \& Lamadrid-Figueroa, H. (2016). Lead in candy consumed and blood lead levels of children living in Mexico City. Environmental Research, 147, 497-502.https://doi.org/10.1016/j.envres.2016.03.007

Taupeau, C., Poupon, J., Nome, F. \& Lefevre, B. (2001). Lead accumulation in the mouse ovary after treatment-induced follicular atresia. Reproductive Toxicology, 15, 385-391. https://pubmed.ncbi.nlm.nih.gov/11489594/, https://doi. org/10.1016/s0890-6238(01)00139-3

Taupeau, C., Poupon, J., Treton, D., Brosse, A., Richard, Y. \& Machelon, V. (2003). Lead reduces messenger RNA and protein levels of cytochrome p450 aromatase and estrogen receptor B in human ovarian granulosa cells. Biology of Reproduction, 68, 1982-1988. https://pubmed. ncbi.nlm.nih.gov/12606482/, https://doi.org/10.1095/ biolreprod.102.0098944

Titus, S., Li, F., Stobezki, R., Akula, K., Unsal, E., Jeong, K., Dickler, M., Robson, M., Moy, F., Goswami, S. \& Oktay, K. (2013). Impairment of BRCA1-Related DNA double-strand break repair leads to ovarian aging in mice and humans. Fertility, 5, 172 pp. https://europepmc. org/article/PMC/5130338, https://doi.org/10.1126/ scitranslmed.3004925

Valdivia-Infantas, M. M.(2005). Intoxicación por plomo. Revista de la Sociedad Peruana de Medicina Interna. 18(1), 22-27.

Winiarska-Mieczan, A. \& Kwiecien, M. (2016). The effect of exposure to $\mathrm{Cd}$ and $\mathrm{Pb}$ in the form of a drinking water or feed on the accumulation and distribution of these metals in the organs of growing Wistar rats. Biological Trace Element Research, 169, 230-236. https://europepmc.org/ article/MED/26113310, https://doi.org/10.1007/s12011015-0414-4

Wu, X., Cobbina, S.J., Mao, G., Xu, H., Zhang, Z. \& Yang, L. (2016). A review of toxicity and mechanisms of individual and mixtures. Environmental Science and Pollution Research, 23 (9), 8244-8259. https://pubmed. ncbi.nlm.nih.gov/26965280/, https://link.springer.com/ article/10.1007\%2Fs 11356-016-6333-x, 10.1007/s11356016-6333-X

Xu, L. H. Mu, F. F., Zhao, J. H., He, Q., Cao, C. L., Yang, H., Liu, Q., Liu, X. H. \& Sun, S. J. (2015). Lead Induces Apoptosis and Histone Hyperacetylation in Rat Cardiovascular Tissues. PLoSONE, 10(6), e0129091. https://journals.plos. org/plosone/article?id=10.1371/journal.pone.0129091, https://doi.org/10.1371/journal.pone.0129091

Zuo, P., Qu, W., Cooper, R. N., Goyer, R. A., Diwan, B. A. \& Waalkes, M. P. (2009). Potential role of $\boldsymbol{\alpha}$-synuclein and metallothionein in lead-induced inclusion body formation. Toxicological Sciences, 111, 100-108. https:// doi.org/10.1093/toxsci/kfp132 